\title{
Facile Synthesis of Struvite from Municipal Wastewater Using Pre-Treated Magnesite
}

\author{
A. Mavhungu, K. Mbaya, V Masindi, K.L. Muedi and L Mpenyana-Monyatsi
}

\begin{abstract}
In this study, the use of South African, vibratory ball milled and calcined cryptocrystalline magnesite was used for the synthesis of struvite. Employed conditions were observed to be 30 mins of mixing, $1 \mathrm{~g}$ of dosage at $1 \mathrm{~g}: 100 \mathrm{~mL} \mathrm{~S} / \mathrm{L}$ ratios. The product mineral was analyzed using $\mathrm{X}$-ray diffraction and FT-IR. The water quality was observed to be safer for irrigation and discharge purposes. In that regard, this study successfully proved that the use of locally available cryptocrystalline magnesite is viable and it can be used to sustainably manage effluents emanating from municipal wastewater treatment process.
\end{abstract}

Keywords - magnesite, effluent, struvite, treatment

\section{INTRODUCTION}

As a result of a drastic population growth, South Africa is facing a serious water crisis. This is associated with an increase in population size which directly increases the demand of fresh water resources. High demand and usage of clean water resources lead to the generation of an increased volume of wastewater to the water treatment facilities. However, water treatment facilities were designed to cater for a known volume of water but when the water influx exceeds the treatment capacity of the wastewater treatment plant. The quality of product water is compromised hence perpetuating the environmental impacts [1-4].

Municipal effluents are mainly rich in nitrates, phosphates and ammonium nitrates amongst other pollutants. These pollutants are originating from industrial and domestic activities leading to the generation of pollutants that are rich in organic and inorganic pollutants. More prevalently, municipal wastewaters are rich in organic pollutants from human wastes and other domestic processes. These wastes are treated through aerobic and non-aerobic decomposition processes. However, if the wastes are not properly and adequately treated, the resultant water is rich in nitrate and phosphate [3-6].

A. Mavhungu and K. Mbaya, Department of Chemical, Metallurgy and Materials Engineering, Staatsartillirie Rd, Pretoria West 0183, Tshwane, University of Technology, Pretoria, South Africa

V Masindi and K.L. Muedi Council for Scientific and Industrial Research (CSIR), Built Environment (BE), Hydraulic Infrastructure Engineering (HIE), P.O Box 395, Pretoria, 0001, South Africa,

V Masindi, Department of Environmental Sciences, School of Agriculture and Environmental Sciences, University of South Africa (UNISA), P. O. Box 392, Florida, 1710, South Africa

L Mpenyana-Monyatsi, Department of Environmental, Water and Earth Sciences, Faculty of Science, Tshwane University of Technology, Private Bag X680, Pretoria, 0001, South Africa
Phosphates and nitrates have been documented to pose serious challenges in the aqua-sphere due to enrichment of waterbodies with nutrients[4]. They promote the rapid growth of aquatic plants and when those plants die, they deplete the water dissolved oxygen hence suffocating aquatic organisms. Dead plants also affect the aesthetic value of the river ecosystem hence reducing its economic value. High loads of nitrates also lead to a number of medical conditions as reported in epidemiological reports [1-3].

In the quest to manage high levels of phosphates and nitrates and the endeavours to curtail its impacts, researchers have developed a number of technologies for the removal of the said pollutants. The technologies involve the use of adsorbents [7], precipitants [8], filters [9], phytoremediation [10,11], and ion exchange resins [12] to remove high levels of phosphates. Adsorption is a widely used technology for the removal of pollutants from water but it challenge is limited efficiency in concentrated solution and the requirement of the adsorbent to be regenerated frequently. This limits its application on a larger scale [13]. Recently, researchers have focused attention on adding a precursor to synthesize struvite from wastewater as shown in Eqn. 1 [14].

$$
\mathrm{Mg}^{2+}+\mathrm{NH}_{4}^{+}+\mathrm{PO}_{4}^{3-}+6 \mathrm{H}_{2} \mathrm{O} \rightarrow \mathrm{MgNH}_{4} \mathrm{PO}_{4} \cdot 6 \mathrm{H}_{2} \mathrm{O}
$$

Researchers have explored the use of magnesium-based-salts (magnesium hydroxide $\left(\mathrm{Mg}(\mathrm{OH})_{2}\right)$, magnesium oxide and magnesium chloride, $\left(\mathrm{MgCl}_{2}\right)$ as magnesium inputs for struvite production [14]. These are commercial cost and it also inflates the operational cost of the proposed technology. The Council for Scientific and Industrial Research (CSIR) in South Africa, Pretoria, has patented the use of pre-treated magnesite for water amelioration and product minerals valorisation. However, they never explored the use of their pre-treated magnesite for the synthesis of struvite. However, Masindi et al. (2016) successfully proved that the Folovhodwe cryptocrystalline magnesite can be successfully used for the removal of phosphate from municipal wastewater but its application for the synthesis of struvite was not explored. This will then be the first study in design and execution to explore the use of pre-treated South African cryptocrystalline magnesite for the synthesis of struvite. Masindi et al. (2015) reported that approximately 60 megatons of magnesites deposits are available in South Africa. This will ensure sustainability and security in the country since the material will be locally available and abundant. The synthesized materials will also be used as additives in agricultural fields. 


\section{MATERIALS AND METHODS}

\section{A. Sampling}

Raw phosphate and ammonium rich effluents were collected in a sealed in high-density polyethylene (HDPE) plastic bottles from a municipal wastewater treatment facility. The solids and debris in the water samples were removed by filtration using a Whitman filter. Samples were stored at $4^{\circ} \mathrm{C}$ until use for optimisation experiments and the struvite synthesis. The entire chemical used in this study were of analytical grades.

\section{B. Treatment at optimized conditions}

All adsorption experiments were performed in High Density Poly-Ethylene (HDPE) flasks using overhead stirrers at 500 rpm. Optimum conditions were observed to be 30 mins of mixing, $1 \mathrm{~g}$ of dosage at $1 \mathrm{~g}: 100 \mathrm{~mL} \mathrm{~S} / \mathrm{L}$ ratios. All experiments were conducted in triplicates and the data was reported as mean value.

\section{Quality control and assurance}

To ensure results creditability and trustworthy, experiments were conducted in triplicate and reporting the data as mean value with Standard deviations (SD). Data was considered acceptable when percentage difference within triplicate samples and percentage error were below $10 \%$. The analytical values below detection limit (BDL) were managed according to EPA guideline [15]. The accuracy of the analysis was monitored by analysis of National Institute of Standards and Technology (NIST) water standards. Inter-laboratory analysis was also done to further verify the validity of the results where only accredited laboratories were used for this matter.

\section{Characterization of the synthesized struvite}

Crystal mineral phases in the feed and recovered materials were determined using X-ray Diffraction (XRD) (Philips PW 1710 Diffractometer; graphite secondary monochromatic source). X-ray fluorescence (XRF) (Thermo Fisher ARL-9400 XP+ Sequential XRF equipped with WinXRF software) was used to determine the elemental constituents. Mapping and morphology of the materials were examined using an Auriga Cobra FIB FESEM instrument high resolution scanning electron microscope (HR- SEM) with the precision milling and nanofabrication abilities of high resolution focused ion beam (FIB) at an accelerating voltage of $3 \mathrm{KeV}$ (Model: Sigma VP FE-SEM with Oxford EDS Sputtering System, Make: Carl Zeiss, Supplier: Carl Zeiss, USA). Metal functional groups present under transmittance mode were investigated using Perkin-Elmer Spectrum 100 Fourier Transform Infrared Spectrometer (FTIR) equipped with a Perkin-Elmer Precisely Universal Attenuated Total Reflectance (ATR) sampling accessory equipped with a diamond crystal. The thermal stability was determined using a Thermo Gravimetric Analyser (TGA Q500, TA instrument) under air atmosphere with a flow rate of $50 \mathrm{~mL} / \mathrm{min}$ and a heating rate of $10^{\circ} \mathrm{C} / \mathrm{min}$.

\section{RESULTS AND DISCUSSIONS}

\section{A. Characterisation of the synthesized struvite}

The mineralogical composition, functional groups, elemental compositions, morphological properties, and thermal stability of synthesized material were reported in Tables and Figures below.

\section{B. Mineralogical composition}

The crystalline phases in a diffractogram of the synthesized product are depicted in Figure 1 below.

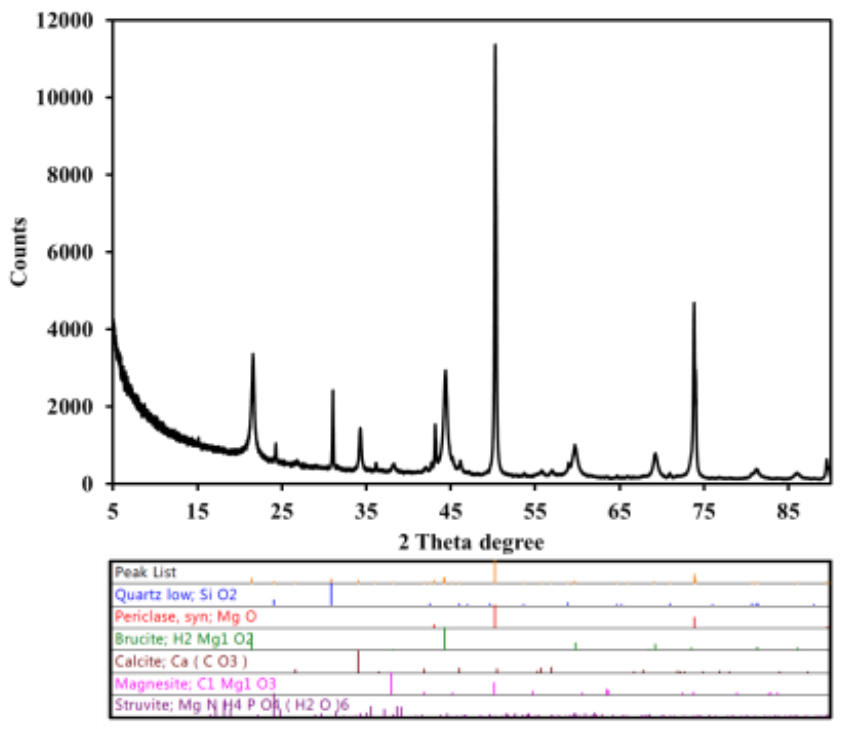

Fig. 1. Diffractogram of the synthesised material

As shown in Figure 1, the synthesized product was observed to contain quartz, periclase, brucite, calcite, magnesite and struvite. This may be attributed to the feed material that contains quartz, periclase, brucite, calcite, and magnesite as reported by Masindi et al. (2017). The genesis of struvite at 29: 20, 23, 24, 25,36 and 37 is an indication of the crystal phases of struvite. Similar results were reported by Sutiyono, et al. [14]. This is a confirmation that the reaction is leading to the formation of struvite. The other components are also essential because the anticipated use of the synthesized material is for agriculture.

\section{Fourier transforms infrared spectroscopy analysis}

The Fourier transforms infrared spectroscopy analysis of the synthesized product is shown in Figure 2.

TABLE I: THE FUNCTIONAL GROUPS AND WAVENUMBER OF THE SYNTHESIZED PRODUCT

\begin{tabular}{|l|l|l|}
\hline Functional group & Wavenumber & Reference \\
\hline $\mathrm{Mg}-\mathrm{O}$ & $800 \mathrm{~cm}^{-1}$ & {$[16]$} \\
\hline $\mathrm{PO}_{4}^{3-}$ & $1070 \mathrm{~cm}^{-1}$ & {$[16]$} \\
\hline $\mathrm{N}-\mathrm{H}$ & $1475 \mathrm{~cm}^{-1}$ & {$[16]$} \\
\hline$-\mathrm{OH}$ & $3700 \mathrm{~cm}^{-1}$ & {$[16]$} \\
\hline
\end{tabular}




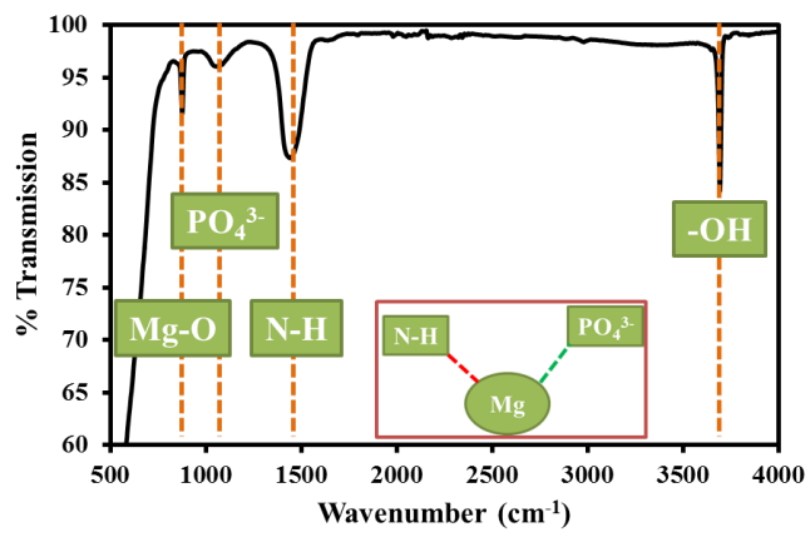

Fig. 2. The Fourier transforms infrared spectroscopy analysis of the synthesized product

From the FT-IR results, the FT-IR spectrum proves the existence of water hydration, $\mathrm{Mg}-\mathrm{O}$ metal-oxygen bond, $\mathrm{N}-\mathrm{H}$ bond, and $\mathrm{PO}_{4}^{3-}$ hence confirming that struvite has been formed. The obtained results are agreement with results reported in literature [16]. The obtained results corroborate the $\mathrm{XRF}$ and XRD results.

\section{Elemental composition}

The elemental composition of the synthesized product is shown in Table 2 below.

As shown in Table 2, the synthesized product was observed to be dominated by $\mathrm{Mg}$ and $\mathrm{P}$ as main components in addition to traces of $\mathrm{Si}, \mathrm{Ca}, \mathrm{Al}, \mathrm{Fe}$ and $\mathrm{S}$. This corroborates the XRD results which indicated the presence of struvite, calcite, periclase, magnesite, and quartz.

TABLE II: ELEMENTAL COMPOSITION OF THE SYNTHESIZED MATERIAL

\begin{tabular}{|c|c|c|c|}
\hline \multirow[b]{2}{*}{ Elements } & \multicolumn{2}{|c|}{ SARM49 } & \multirow[b]{2}{*}{ Struvite } \\
\hline & Certified & Analysed & \\
\hline $\mathrm{SiO}_{2}$ & 99.6 & 99.70 & 2.93 \\
\hline $\mathrm{TiO}_{2}$ & 0.01 & 0.00 & 0.00 \\
\hline $\mathrm{Al}_{2} \mathrm{O}_{3}$ & 0.05 & 0.01 & 0.14 \\
\hline $\mathrm{Fe}_{2} \mathrm{O}_{3}$ & 0.05 & 0.01 & 0.16 \\
\hline MnO & 0.01 & 0.00 & 0.00 \\
\hline $\mathrm{MgO}$ & 0.05 & 0.01 & 32.40 \\
\hline $\mathrm{CaO}$ & 0.01 & 0.01 & 4.76 \\
\hline $\mathrm{Na}_{2} \mathrm{O}$ & 0.05 & 0.02 & $<0,01$ \\
\hline $\mathrm{K}_{2} \mathrm{O}$ & 0.01 & 0.01 & $<0,01$ \\
\hline $\mathrm{P}_{2} \mathrm{O}_{5}$ & 0 & 0.03 & 40.14 \\
\hline $\mathrm{Cr}_{2} \mathrm{O}_{3}$ & 0 & 0.00 & 0.02 \\
\hline $\mathrm{NiO}$ & 0 & 0.01 & $<0,01$ \\
\hline $\mathrm{ZrO}_{2}$ & 0 & 0.01 & $<0,01$ \\
\hline $\mathrm{SO}_{3}$ & 0 & 0.00 & 0.39 \\
\hline $\mathrm{WO}_{3}$ & 0 & 0.00 & $<0,01$ \\
\hline $\mathrm{CuO}$ & 0 & 0.00 & $<0,01$ \\
\hline $\mathrm{CO}_{3} \mathrm{O}_{4}$ & 0 & 0.00 & $<0,01$ \\
\hline SrO & 0 & 0.00 & 0.02 \\
\hline LOI & 0 & 0.10 & 19.00 \\
\hline Total & 100 & 99.94 & 99.96 \\
\hline
\end{tabular}

The Fourier transforms infrared spectroscopy analysis of the synthesized product

\section{E. Morphological properties}

The morphological properties of the synthesized product are depicted in Figure 3 below.

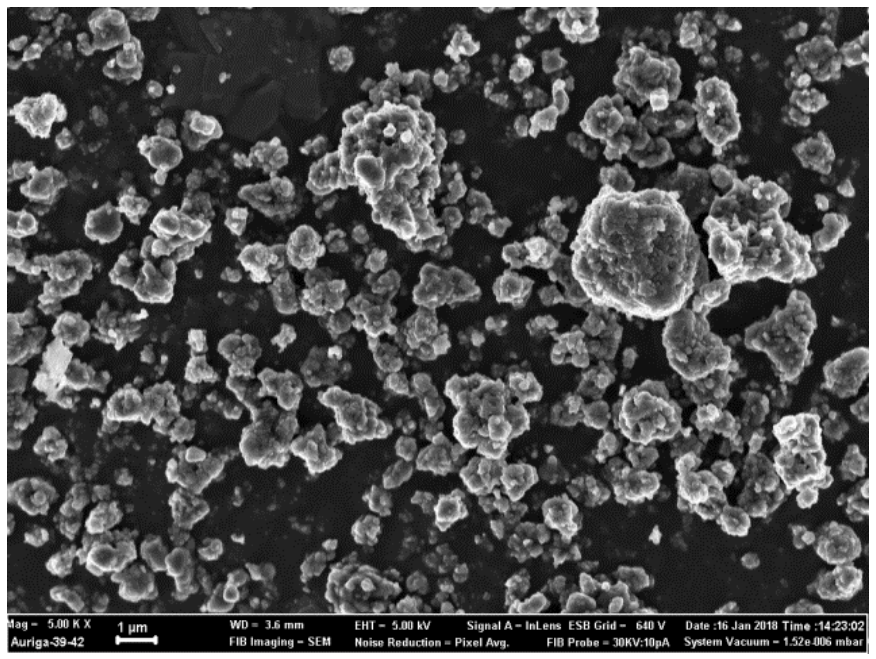

Fig. 3. The morphological properties of the synthesized material As shown in Figure 3, the morphology of synthesized material portrayed sheet-like spherical structures. This is consistent to what have been reported for struvite in literature [16].

\section{F. Thermal stability analysis}

The thermal stability of the synthesized product is shown in Figure 4.

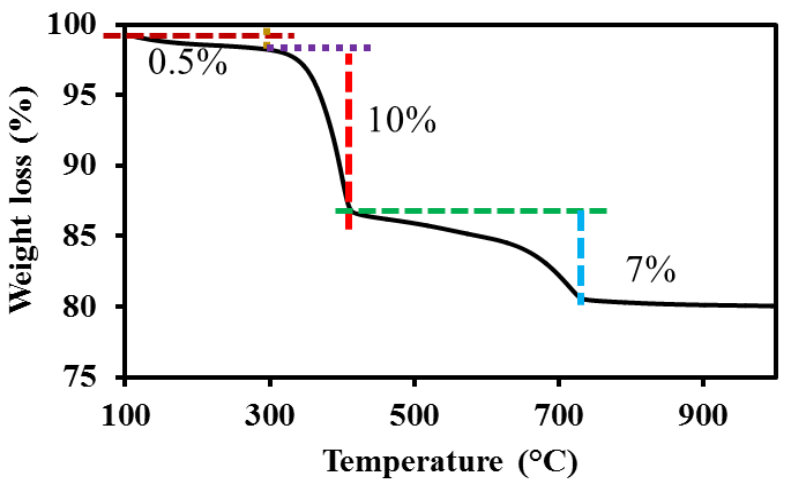

Fig. 4. Thermal stability of the synthesized product

As shown in Figure 4, the thermal analysis of the synthesized material was evaluated. The results show the loss of moisture contents, impurities and volatile mater from the matrices of the synthesized material. This is consistent to what has been reported in literature. 


\section{CONCLUSIONS}

In this study, the synthesis of struvite from municipal effluent using a vibratory ball milled and calcined cryptocrystalline magnesite was successfully accomplished. Experimental results revealed that $60 \mathrm{~min}$ of mixing, $1 \mathrm{~g}$ of dosage at $1 \mathrm{~g}: 100 \mathrm{~mL} \mathrm{~S} / \mathrm{L}$ ratios, $\mathrm{pH}>10$ and $25-35{ }^{\circ} \mathrm{C}$ temperature are the suitable conditions for the synthesis of struvite using a vibratory ball milled and calcined cryptocrystalline magnesite. X-ray diffraction further confirmed the synthesis of struvite from treatment process. In that regard, this study successfully proved that the use of locally available cryptocrystalline magnesite is viable and it can be used to sustainably manage effluents emanating from municipal wastewater treatment by benefiting their waste by converting them into resources such as struvite and clean water. This also communicates with the process of circular economy and zero-liquid-discharge approach in terms of waste management

\section{REFERENCES}

[1] Masindi, W. Gitari, K. Pindihama, Synthesis of nanocomposite of cryptocrystalline magnesite-bentonite clay and its application for phosphate removal from municipal effluents, Environ. Technol., (2015) $1-27$.

[2] V. Masindi, W. Gitari, K. Pindihama, Synthesis of nanocomposite of cryptocrystalline magnesite-bentonite clay and its application for phosphate removal from municipal effluents, Environ. Technol., (2015) $1-27$.

[3] V. Masindi, W. Gitari, K. Pindihama, Adsorption of phosphate from municipal effluents using cryptocrystalline magnesite: complementing laboratory results with geochemical modelling, Desalination and Water Treatment, (2015) 1-13. https://doi.org/10.1080/19443994.2015.1110720

[4] M.M. Rahman, M.A.M. Salleh, U. Rashid, A. Ahsan, M.M. Hossain, C.S. Ra, Production of slow release crystal fertilizer from wastewaters through struvite crystallization - A review, Arabian Journal of Chemistry, 7 (2014) 139-155. https://doi.org/10.1016/j.arabjc.2013.10.007

[5] K. Yetilmezsoy, F. Ilhan, E. Kocak, H.M. Akbin, Feasibility of struvite recovery process for fertilizer industry: A study of financial and economic analysis, Journal of Cleaner Production, 152 (2017) 88-102. https://doi.org/10.1016/j.jclepro.2017.03.106

[6] V. Masindi, W.M. Gitari, K.G. Pindihama, Synthesis of cryptocrystalline magnesite/bentonite clay composite and its application for removal of phosphate from municipal wastewaters, Environ Technol, (2015) 1-10.

[7] V. Masindi, W.M. Gitari, K.G. Pindihama, Adsorption of phosphate from municipal effluents using cryptocrystalline magnesite: complementing laboratory results with geochemical modelling, Desalination and Water Treatment, (2015) 1-13. https://doi.org/10.1080/19443994.2015.1110720

[8] S. Gypser, F. Hirsch, A.M. Schleicher, D. Freese, Impact of crystalline and amorphous iron- and aluminum hydroxides on mechanisms of phosphate adsorption and desorption, Journal of Environmental Sciences, (2017).

[9] J.S. Freeman, D.L. Rowell, The adsorption and precipitation of phosphate onto calcite, J. Soil Sci., 32 (1981) 75-84. https://doi.org/10.1111/j.1365-2389.1981.tb01687.x

[10] Y. Yang, J. Lohwacharin, S. Takizawa, Hybrid ferrihydrite-MF/UF membrane filtration for the simultaneous removal of dissolved organic matter and phosphate, Water Res., 65 (2014) 177-185. https://doi.org/10.1016/j.watres.2014.07.030

[11] L.A. Wendling, P. Blomberg, T. Sarlin, O. Priha, M. Arnold, Phosphorus sorption and recovery using mineral-based materials: Sorption mechanisms and potential phytoavailability, Appl. Geochem., 37 (2013) 157-169.

https://doi.org/10.1016/j.apgeochem.2013.07.016
[12] Z. Zeng, S.D. Zhang, T.Q. Li, F.L. Zhao, Z.L. He, H.P. Zhao, X.E. Yang, H.L. Wang, J. Zhao, M.T. Rafiq, Sorption of ammonium and phosphate from aqueous solution by biochar derived from phytoremediation plants, Journal of Zhejiang University: Science B, 14 (2013) 1152-1161. https://doi.org/10.1631/jzus.B1300102

[13] N.I. Chubar, V.A. Kanibolotskyy, V.V. Strelko, G.G. Gallios, V.F. Samanidou, T.O. Shaposhnikova, V.G. Milgrandt, I.Z. Zhuravlev, Adsorption of phosphate ions on novel inorganic ion exchangers, Colloids Surf. Physicochem. Eng. Aspects, 255 (2005) 55-63. https://doi.org/10.1016/j.colsurfa.2004.12.015

[14] V. Masindi, J.G. Ndiritu, J.P. Maree, Fractional and step-wise recovery of chemical species from acid mine drainage using calcined cryptocrystalline magnesite nano-sheets: An experimental and geochemical modelling approach, Journal of Environmental Chemical Engineering, 6 (2018) 1634-1650. https://doi.org/10.1016/j.jece.2018.02.005

[15] S. Sutiyono, L. Edahwati, D.S. Perwitasari, S. Muryanto, J. Jamari, A.P. Bayuseno, Synthesis and Characterisation of Struvite Family Crystals by An Aqueous Precipitation Method, MATEC Web of Conferences, 58 (2016) 01006.

[16] X. Wei, R.C. Viadero Jr, K.M. Buzby, Recovery of iron and aluminum from acid mine drainage by selective precipitation, Environmental Engineering Science, 22 (2005) 745-755. https://doi.org/10.1089/ees.2005.22.745

[17] E. Heraldy, F. Rahmawati, Heriyanto, D.P. Putra, Preparation of struvite from desalination waste, Journal of Environmental Chemical Engineering, 5 (2017) 1666-1675.

https://doi.org/10.1016/j.jece.2017.03.005

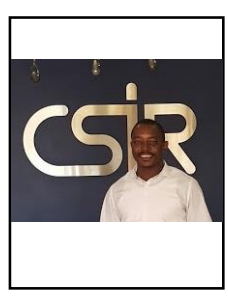

Dr. Vhahangwele Masindi (Pr. Nat. Sci.) is a principal researcher in the council for scientific and Industrial Research (CSIR). He is born in Mukula Village, Thohoyandou, Limpopo province, South Africa. He holds a PhD degree in Environmental Science from the University of Venda, Thohoyandou, South Africa, 2015. He is also a Research Fellow in the University of South Africa, Pretoria, South Africa. He is also a Part-Time lecturer in the University of Venda, Thohoyandou, South Africa. He has published numerous papers in high impact factor and prestigious international journals. He has also written a number of book chapters. In addition to that, he has filed two PCT patents in the state, Australia and other countries. He also has a number of postgraduate students who graduated under his academic supervision. He is also a recipient of numerous awards in his research domain. 